\title{
UWB Notch Antennas in MIMO System with High Isolation Performance
}

\author{
Donya Z. NAZIF', Ibrahim S. MOHAMED ${ }^{2}$, Abdelhamid A. GAAFAR ${ }^{1}$, Mahmoud A. ABDALLA ${ }^{2}$ \\ ${ }^{1}$ Electronics and Communication Department, Arab Academy for Science and Technology, Cairo, Egypt \\ ${ }^{2}$ Electronic Engineering Department, Military Technical College, Cairo, Egypt \\ maaabdalla@ieee.org
}

Submitted July 1, 2020 / Accepted October 21, 2020

\begin{abstract}
This article presents a detailed analysis and design of an ultra-wideband $(3.1 \mathrm{GHz}-10.6 \mathrm{GHz})$ notch antennas in a two-element MIMO system with high isolation performance. The wideband spectrum is notched at the WiMAX band at $5.8 \mathrm{GHz}$ center frequency using a highly selective electromagnetic bandgap structure coupled to the antenna feeding lines. An array of electromagnetic bandgap structure is used to achieve wideband isolation between the two elements. The two antenna elements achieve wideband reflection coefficient for good matching below $-10 \mathrm{~dB}$, except the notch where it becomes higher than $-2 d B$. On the other hand, the antenna elements have a minimum of $20 \mathrm{~dB}$ isolation. Thanks to the achieved results, the antenna MIMO elements have small envelope correlation (less than 0.05) and also small channel capacity loss (less than $0.2 \mathrm{bit} / \mathrm{s} / \mathrm{Hz}$ ). The obtained results are verified using experimental measurements and all circuit/ EM needed simulations.
\end{abstract}

\section{Keywords}

Multi-Input-Multi-Output (MIMO), notched-UWB antenna, electromagnetic bandgap (EBG) array, envelope correlation, diversity

\section{Introduction}

Wideband of mutual coupling reduction in multiple input multiple output (MIMO) systems, is considered a challengeable aim for the RF front end researchers. $\mathrm{Mu}-$ tual coupling degradation is an important constraint issue for MIMO applications that are used in order to enhance the spectrum efficiency, channel capacity and system reliability. The correlation between the MIMO elements is decreased when the mutual coupling is reduced. In order to let the MIMO system operates at high performance with high data rates and increased signal to noise ratio (SNR) [1], the envelope correlation coefficient (ECC) between the MIMO elements should be lower than 0.5 .

Different techniques have been used to solve such problem of mutual coupling as etching uniform/non-uniform structures in the ground plane which known as de- fected ground structures [3] using some decoupling circuits for compensating the mutual impedance due to the mutual coupling [3],[4], and metamaterial structures which are famous with negative $\mu / \varepsilon$ feature or even with double negative constitutive parameters to get negative refractive index material for the sake of surface waves blocking [5]. Other attempts have been introduced to reduce the mutual coupling in the UWB antennas area by adding different shapes of stubs [6]. Electromagnetic bandgap structures (EBG) have been employed with different configurations to solve this problem [7]. Also, asymmetric coplanar waveguide configuration is used in [8] to reduce the undesired mutual coupling.

Since the ultrawideband (UWB) antennas are considered good candidates in imaging via fast wireless applications which need a high data rate, caused in huge demand on such antennas, lately, [10]. The Federal Communications Commission (FCC) has selected ultrawideband (UWB) communication to be within the bandwidth of $3.1 \mathrm{GHz}$ to $10.6 \mathrm{GHz}$ in 2002 [11]. In order to overcome interferences with WiMAX services in $3 / 5 \mathrm{GHz}$ bands, some significant work have been published to notch this interference using mushroom like electromagnetic bandgap structures [12-14]. Over the past decade, UWB antennas have been applied in MIMO systems to handle emerged high data rate, improve higher multiplexing gain and capacity links [15]. However, the challenge in these systems is how to maintain good MIMO performance over the wideband. The trade-off in these attempts is the small size and the achieved coupling between elements. This problem has been addressed in many recent works [16-24]. In specific explanation, example for these solution attempts is using directional UWB MIMO radiators [16]. Another approach is using asymmetric configurations of the radiated monopoles [8]. In [17], two inverted L-shape parasitic strips/stubs are used to obtain UWB MIMO antenna using an etched slot in the ground plane for enhancing the isolation between the elements. This technique has enhanced the isolation in $2.2-5.2 \mathrm{GHz}$ band and in $8.2-10.2 \mathrm{GHz}$ band, but the reflection coefficient on $3-5.5 \mathrm{GHz}$ band has become worse. In [18], UWB antennas of two triangular shaped elements with a common ground are isolated through adding T-crossed shaped stub in the ground. This approach enhanced the isolation in the bands $3-4 \mathrm{GHz}$ and 
6.2 GHz-8.8 GHz band with approximately $10 \mathrm{~dB}-20 \mathrm{~dB}$ isolation. Other configurations for UWB antennas have been studied where they are decoupled through the opposite orientation for elements [19], etching slots and adding stubs for shared radiator elements [20], using perpendicular orientation for the MIMO elements with a slot between them [21], [22]. In [23] an array of slotted Y-shaped Frequency Selective Surfaces (FSS) is used besides using polystyrene block since the block enhanced the isolation only for the case of opposite antennas in the higher band. In contrast, in the case of orthogonal antennas, isolation has become worse. Also, the large size limits the usage of the MIMO elements. Besides, the notched UWB antennas (with single or dual notches) have noticeable interest in UWB notch MIMO antennas using different shapes of metal strips or stubs in the ground plane [24-35]. However, few researchers used EBG structure due to its narrowband characteristics [36], [37].

In this work, two monopole elements for UWB MIMO antennas are introduced with low coupling between them using different one-dimensional array of mushroomlike EBG structure without affecting the matching over the entire band. The wideband isolation in the MIMO antenna is important to be noticed that it has occurred over the entire UWB spectrum. Also, each antenna element has 5.8 GHz WiMAX service frequencies notched from the UWB spectrum using another narrow band mushroom-like EBG. The detailed design and newly MIMO analysis performance are presented.

\section{UWB Notch Monopole Antenna using EBG}

The reported antenna is an UWB circular monopole antenna whose feeding is centered between two mushroom EBG cells in order to get a notch. The circular monopole antenna is designed with radius $\left(R_{1}\right)$ and fed with a $50 \Omega$ microstrip transmission line of width $\left(W_{\mathrm{f}}\right)$ and length $\left(L_{\mathrm{f}}\right)$. The length of the ground plane below the substrate layer is represented with $\left(L_{\mathrm{g}}\right)$. The antenna layout with the EBG cells that are placed with distances $(S)$ from the feeding line side edges, is shown in Fig. 1(a). The antenna and EBG cell are placed at the top of the substrate (RO4003) with relative permittivity $\left(\varepsilon_{\mathrm{r}}\right)$ of 3.55 , loss tangent $\left(\delta_{\mathrm{n}}\right)$ of 0.0027 and the substrate thickness is $0.813 \mathrm{~mm}$. In the following subsections, the design of the EBG and its cauterizations are discussed. The monopole antenna was initially designed such that its diameter is equal to a quarter wavelength at lower UWB frequency $(3.1 \mathrm{GHz})$ and then optimized through EM simulator [Ansys Electronics Desktop]. The equivalent LC network for the EBG cells can be demonstrated in Fig. 1(b). The single notch frequency within the UWB monopole antenna bandwidth was designed using the EBG design formulas (1)-(5) where $f_{\mathrm{c}}$ is the stopband center frequency, $\Delta f$ is the absolute bandwidth, $B W$ is the fractional bandwidth, and $Q$ is the EBG quality factor. The design objective is to have notch frequency $f_{\mathrm{c}}=5.8 \mathrm{GHz}$

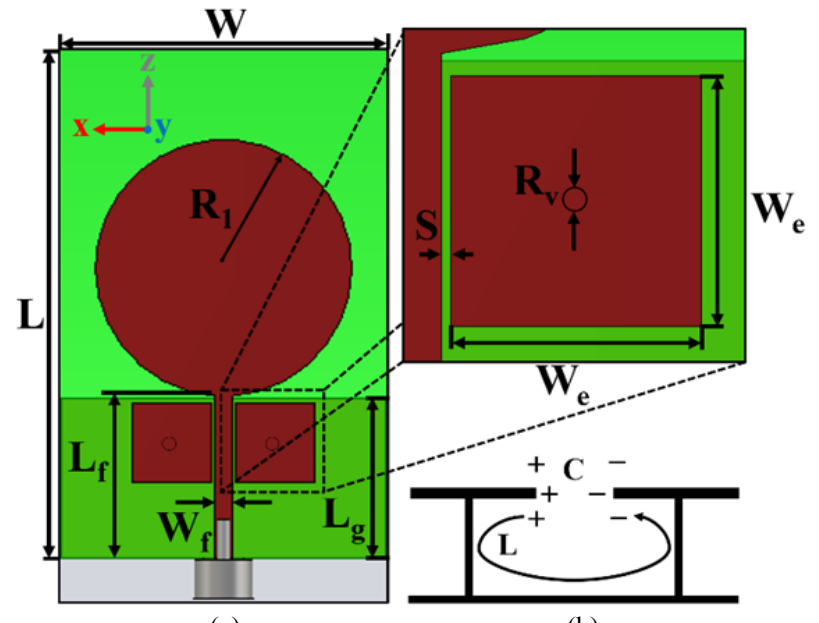

(a)

(b)

Fig. 1. (a) The 1D layout geometry of the UWB notch single antenna, $W=33 \mathrm{~mm}, L=30 \mathrm{~mm}, L_{\mathrm{g}}=16.3 \mathrm{~mm}$, $L_{\mathrm{f}}=16.6 \mathrm{~mm}, R_{1}=13 \mathrm{~mm}, W_{\mathrm{f}}=1.8 \mathrm{~mm}, W_{\mathrm{e}}=8.1 \mathrm{~mm}$, $R_{\mathrm{v}}=0.7 \mathrm{~mm}$, and (b) the EBG equivalent circuit.

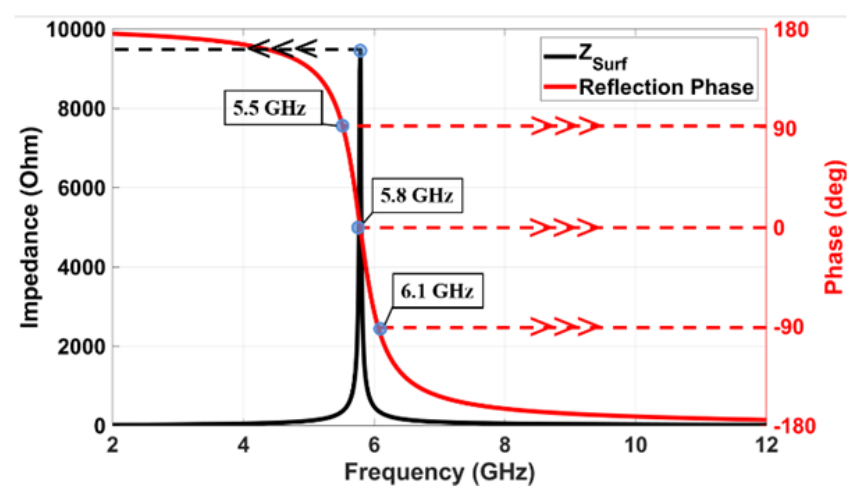

Fig. 2. The surface impedance property and phase reflection for the mushroom EBG

with a narrow bandwidth $(\Delta f=0.6 \mathrm{GHz})$. Synthesis of the EBG dimensions has been done using (1)-(5) and with the help of EM simulator for further optimization.

$$
\begin{gathered}
f_{\mathrm{c}}=\frac{1}{2 \pi \sqrt{L C}}, \\
B W=\frac{\Delta f}{f_{\mathrm{c}}}=\frac{1}{\eta} \sqrt{\frac{L}{C}}, \\
Q=1 / B W=\eta \sqrt{\frac{C}{L}}, \\
L=\mu_{0} h, \\
C=W_{\mathrm{e}} \frac{\varepsilon_{\mathrm{r}}+1}{\pi} \cosh ^{-1}\left(\frac{W_{\mathrm{e}}+S}{S}\right) .
\end{gathered}
$$

For characterizing one EBG cell in infinite periodic analysis, see Fig. 2. It is obvious that the impedance value in the left y-axis is more than $9000 \Omega$ at $5.8 \mathrm{GHz}$, which confirms the high impedance property; also the phase of the reflected wave from the EBG structure is plotted in the 
right y-axis in Fig. 2. Also, it can be noticed that at $5.8 \mathrm{GHz}$, the reflected phase value is $0^{\circ}$. This result confirms that the designed EBG can form an artificial magnetic conductor (AMC) surfaces. The operating bandwidth can be distinguished by $\pm \pi / 2$ phases, which can be distinguished between $5.5 \mathrm{GHz}$ and $6.1 \mathrm{GHz}$. Also, it can be claimed that the behavior of the mushroom-like EBG cells performs a bandgap for the surface wave propagations in the bilateral directions. The bandgap of the EBG structure is shown in Fig. 3, where the bandgap is noticeable in the frequency band between the propagation modes to be from $5.5 \mathrm{GHz}$ to $8.5 \mathrm{GHz}$.

To validate the filtering design of the EBG cell, the simulated antenna reflection coefficient $\left(\mathrm{S}_{11}\right)$ is plotted in Fig. 4. It is obvious that the reflection coefficient is fairly accepted approximated $-10 \mathrm{~dB}$ threshold over the most of UWB frequency range $(3.1 \mathrm{GHz}-10.6 \mathrm{GHz})$. At $5.8 \mathrm{GHz}$, the notch frequency, the simulated reflection coefficient becomes $-2 \mathrm{~dB}$ which confirms the filtering functionality of the EBG structure. Also, in the right Y-axis in Fig. 4, the efficiency for the notched antenna is shown with the red dotted line. It is clear that the antenna has a minimum radiation efficiency of $80 \%$ at $3.8 \mathrm{GHz}$ and fairly exceeds $90 \%$ over most of the UWB frequency band. Except for the notched band, it drops to less than $30 \%$ at $5.8 \mathrm{GHz}$ as it is the notch frequency where no radiation is there.

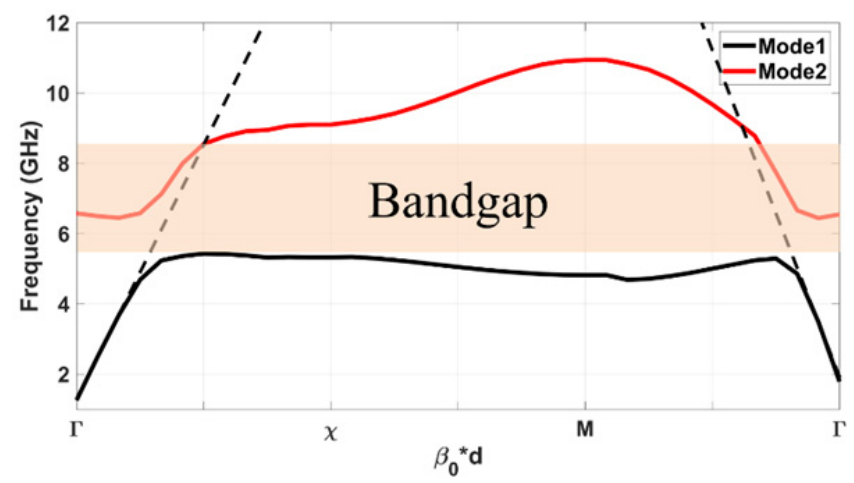

Fig. 3. The simulated $1 \mathrm{D}$ dispersion diagram of the narrow band notching EBG cell.

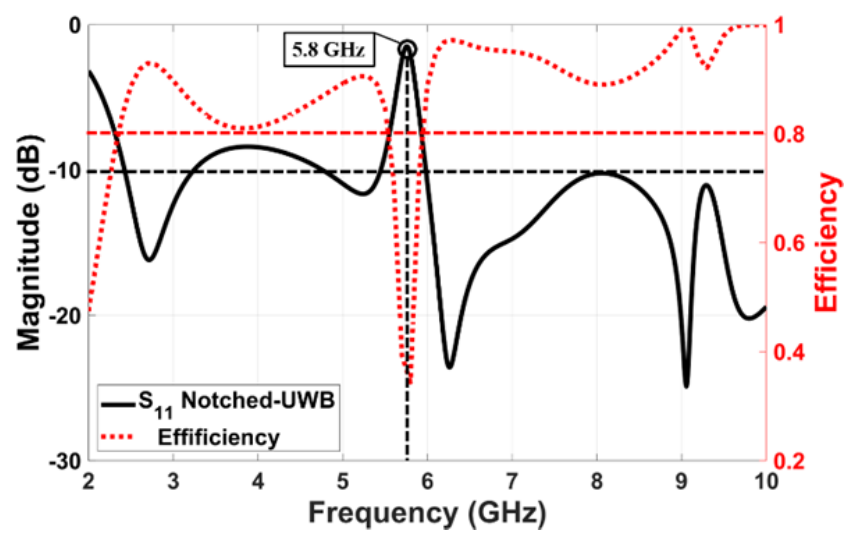

Fig. 4. The simulated antenna reflection coefficient (S11) and the efficiency of the single notched UWB antenna.

\section{UWB Notch MIMO Antenna with Wide Band Isolation}

The design of the proposed UWB notch MIMO antenna with wideband width isolation is studied and explained on the basis of two side antenna elements. The frequency notching and also the isolation will be fulfilled using previously explained mushroom EBG but with a different design to fulfil the two different design objectives. Through this section, the study will introduce the UWB MIMO antennas section, which will be used further as reference. Next, the proposed notched UWB uncorrelated MIMO antenna will be presented compared to the reference one

As shown in Fig. 5, the two beside UWB monopole antenna elements are placed with distance $D=0.4 \lambda_{0}$ apart from center-to-center where $\lambda_{0}$ is the free space wavelength at mid UWB frequency. The simulated and measured Sparameters of the UWB MIMO antenna are shown in Fig. 6 with good agreement between them. The reflection coefficients with the black lines are good enough below $-10 \mathrm{~dB}$ for the whole band, while the transmission coefficients with the red lines represent the maximum and minimum coupling levels within the UWB band of $-10 \mathrm{~dB}$ and $-22 \mathrm{~dB}$, respectively.

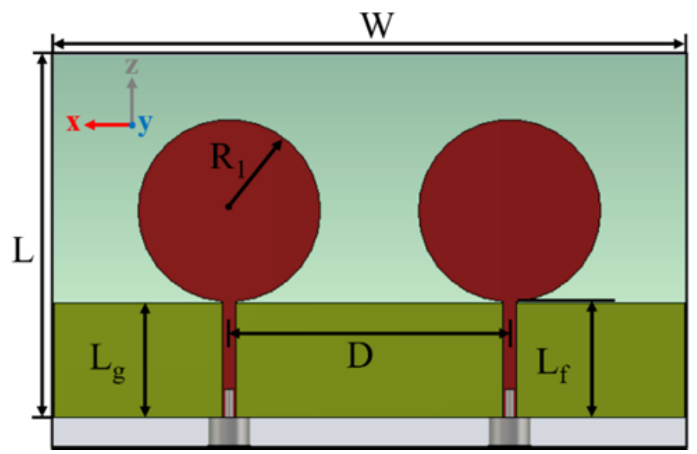

Fig. 5. The layout of a typical MIMO UWB monopole antenna, $W=90 \mathrm{~mm}, \quad L=30 \mathrm{~mm}, \quad D=25 \mathrm{~mm}$, $L_{\mathrm{f}}=16.6 \mathrm{~mm}, L_{\mathrm{g}}=16.3 \mathrm{~mm}, R_{1}=13 \mathrm{~mm}$.

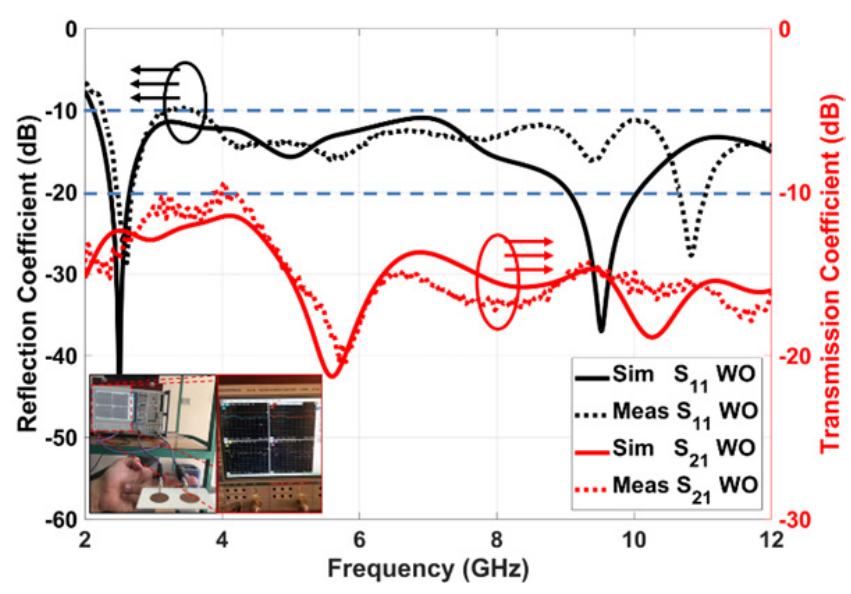

Fig. 6. The simulated and measurement S-parameters for the UWB MIMO antenna without notching and isolation. 


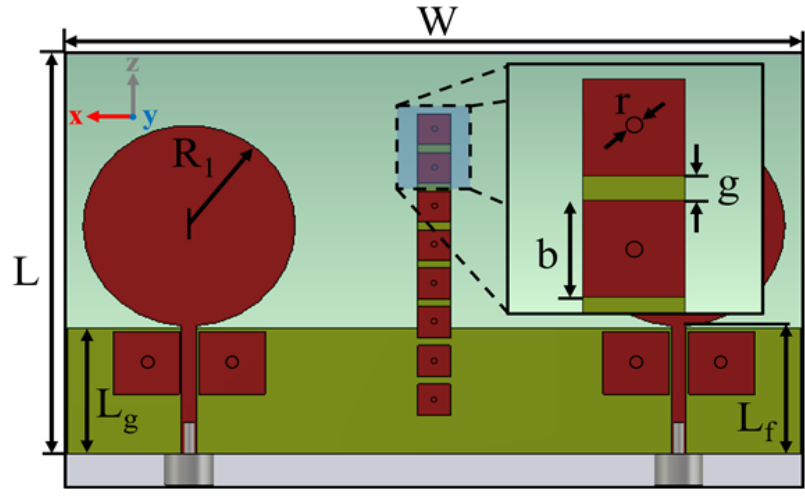

Fig. 7. The layout of uncorrelated UWB MIMO antenna notched at $5.8 \mathrm{GHz}$ with substrate width $b=4 \mathrm{~mm}, r=$ $0.25 \mathrm{~mm}$, and $g=1 \mathrm{~mm}$.

The two correlated UWB MIMO antenna elements in Fig. 5 have been notched using the designed narrowband EBG cell in Fig. 1 . Also, an $8 \times 1$ array of a wideband mushroom EBGs are employed in between the two monopole elements. This configuration is shown in Fig. 7 where the wideband EBG array is printed in the middle between the two radiating elements with an extended strip in the ground plane with the same width of the wideband EBG side. The design of a wideband EBG is objective to increase the isolation between the two elements. This design was done using the former EBG design equation (1)-(4) but with replacing the capacitor formula to be as in (6).

$$
C=W_{\mathrm{e}} \frac{\varepsilon_{\mathrm{r}}+1}{\pi} \cosh ^{-1}\left(\frac{W_{\mathrm{e}}+g}{g}\right) .
$$

In (6), it is obvious that the capacitance definition as replaced the gap between the EBG cell and the feeding line used in the narrowband EBG cell in (5) with the gap between the EBG array elements $(g)$. This wideband EBG isolation was designed at a center frequency $f_{\mathrm{c}}=6.85 \mathrm{GHz}$ and bandwidth $\Delta f=7.5 \mathrm{GHz}$. It is worth to comment that further EM simulations were conducted to optimize the isolation response.

The performance of the uncorrelated UWB MIMO antenna response was examined using the full-wave simulations of scattering parameters magnitudes. The simulated reflection coefficients $\left(S_{11}\right)$ for each case of without (isolation-notching), isolated only and isolated-notched MIMO antenna are cleared in Fig. 8. As it is noticed, there is a good matching level for the three cases, and a notch has occurred at $5.8 \mathrm{GHz}$ for the case of isolated-notched MIMO antenna. In addition, the transmission coefficient $\left(S_{21}\right)$ which is a measure for the coupling levels is enhanced as in Fig. 9 to be $-16 \mathrm{~dB}$ and $-35 \mathrm{~dB}$ for the maximum and minimum coupling values, respectively, for the only-isolated case with the blue dotted line, while $-18 \mathrm{~dB}$ and $-37.5 \mathrm{~dB}$ coupling levels for the isolated-notched case with the red dotted line.

For experimental measurements purposes, a fabricated prototype is shown in Fig. 10. The top and bottom views for

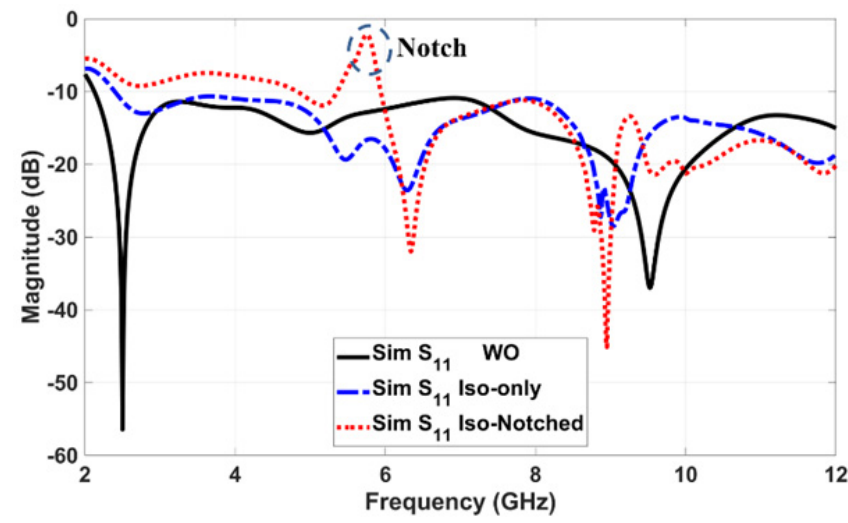

Fig. 8. The simulated reflection coefficients for without, onlyisolated, and isolated-notched cases.

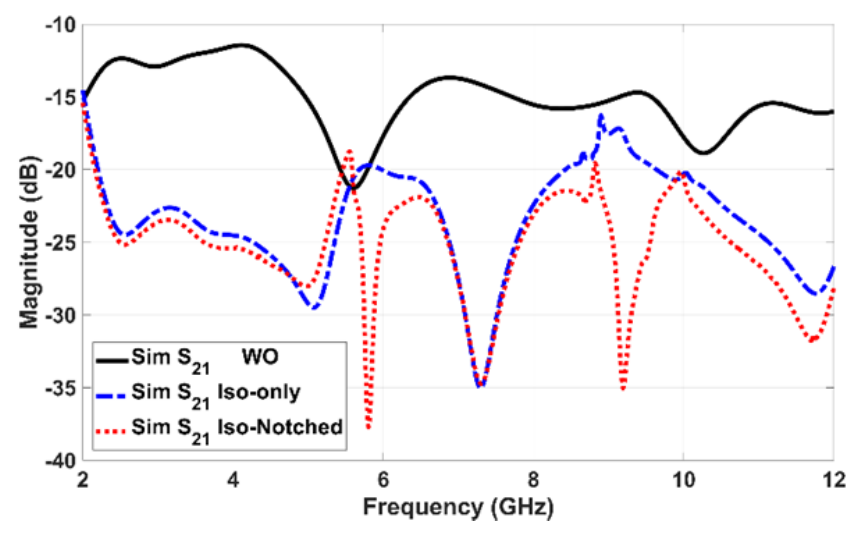

Fig. 9. The simulated transmission coefficients for without, only-isolated, and isolated-notched cases.

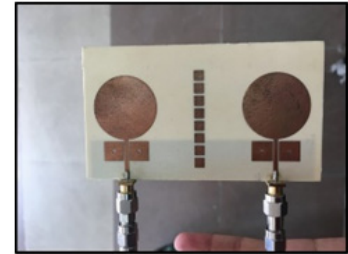

(a)

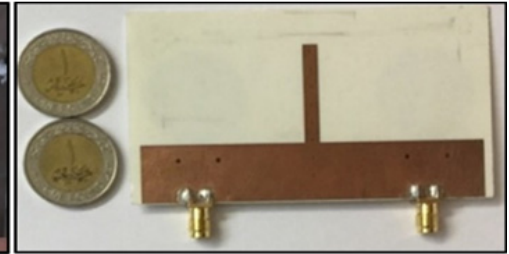

(b)
Fig. 10. The fabricated uncorrelated isolated-notched UWB MIMO antenna (a) top view, and (b) bottom view.

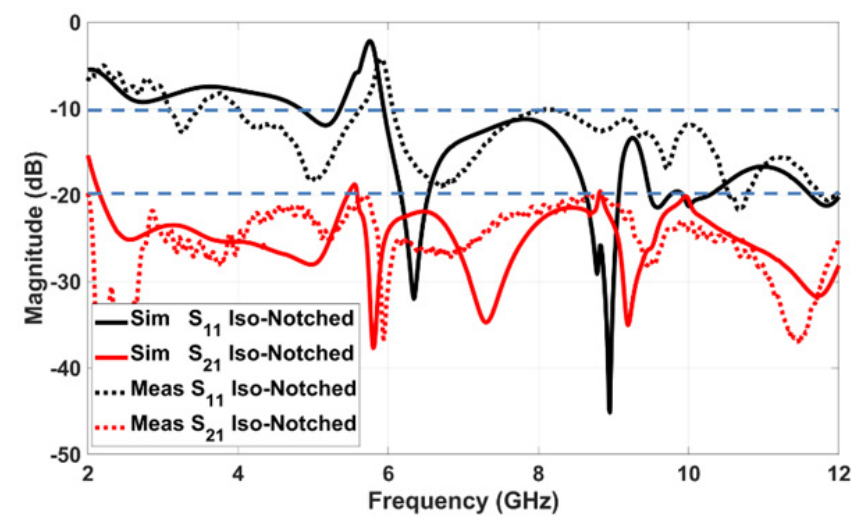

Fig. 11. The simulated and measured S-parameters for the isolated-notched UWB MIMO antenna. 


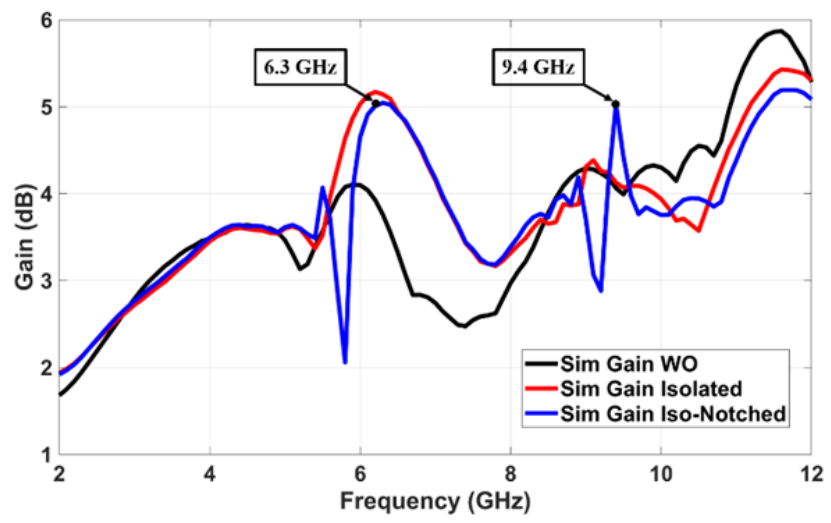

Fig. 12. The simulated gain in all MIMO antenna cases.

the isolated notched MIMO antenna are demonstrated in Fig. 10(a) and Fig. 10(b), respectively. Hence, for verification purpose, experimental measurements were conducted to the fabricated porotype by firstly measuring the scattering parameters using R\&S®ZVA Vector Network Analyzer. Both the simulated and measured scattering parameter magnitudes are shown in Fig. 11.

On the other hand, the frequency-dependent simulated gain is shown in Fig. 12. The gain till $5 \mathrm{GHz}$ is considered nearly the same for all cases, while from 5 till $8.3 \mathrm{GHz}$ the gain is enhanced. After the isolation case only is opposed to a sharp decrease after notching with isolation, especially at $5.8 \mathrm{GHz}$. The highest antenna gain $(5 \mathrm{dBi})$ can be observed at $6.3 \mathrm{GHz}$ and $9.4 \mathrm{GHz}$. Therefore, to examine the functionality of the antenna, the radiation pattern for both $\mathrm{E}$ and $\mathrm{H}$ planes for the MIMO antenna is conducted at $6.3 \mathrm{GHz}$ and $9.4 \mathrm{GHz}$. The radiation patterns for the Eplanes at both frequencies $6.3 \mathrm{GHz}$ and $9.4 \mathrm{GHz}$ are shown in Fig. 13(a) and Fig. 13(b), respectively. Also, the radiation pattern for the H-planes for the former frequencies is shown in Fig. 14(a) and Fig. 14(b), respectively. The radiation patterns were measured using Satimo Starlab chamber and similar patterns performance to the simulation, are compared. It is obvious that there is good agreement between the simulated and measured patterns where the discrepancies may be claimed due to the unavoided fabrication/measurements imperfections and also due to the nature of the low-cost FR4 substrate.

\section{The Uncorrelated MIMO Antenna Parameters Analysis}

Various parameters have been used for MIMO evaluation as follow. The ECC performance is necessary for uncorrelated channels for the sake of channel quality of the UWB MIMO. Also, diversity gain (DG) is an important parameter used to appraise the MIMO system application. Change in correlation in the MIMO system negatively affects diversity gain. Moreover, the multiplexing-efficiency $\eta_{\text {mux }}$ is another essential parameter in MIMO systems that are known with spatial multiplexing rather than diversity [38], [39]. Spatial multiplexing uses MIMO system sub-channels in parallel transferring of diverse data streams.

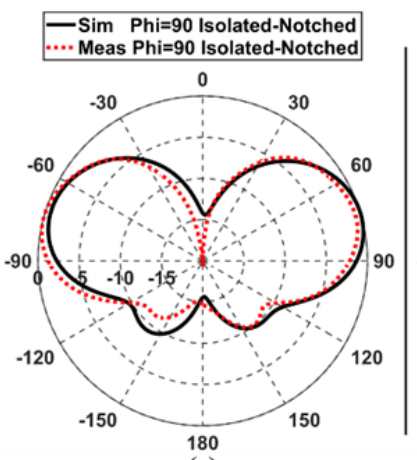

(a)

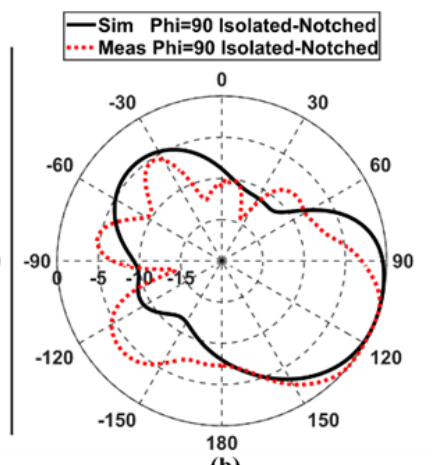

(b)
Fig. 13. The antenna radiation pattern (a) E-plane at $6.3 \mathrm{GHz}$, (b) E-plane at $9.4 \mathrm{GHz}$.
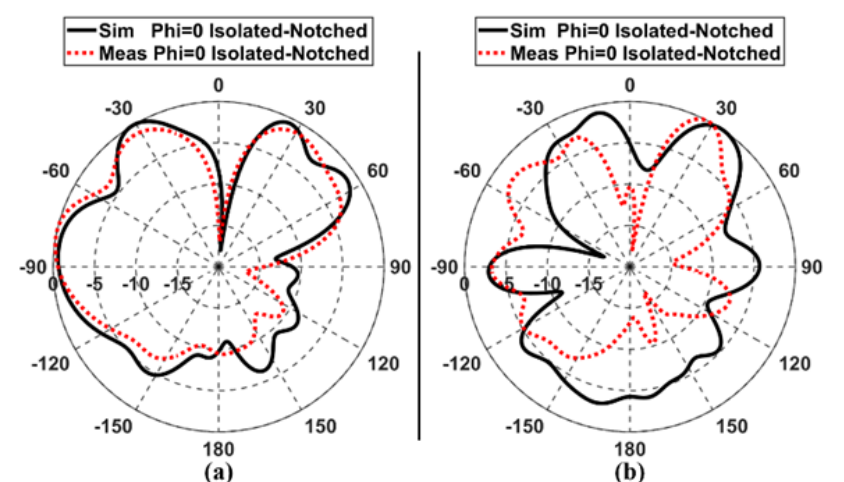

Fig. 14. The antenna radiation pattern (a) H-plane at $6.3 \mathrm{GHz}$, (b) H-plane at $9.4 \mathrm{GHz}$.

Finally, the channel capacity loss (CCL) is used to evaluate the MIMO antennas performance. The CCL rises linearly in respect with increasing the no. of antenna elements in any MIMO system with no change in bandwidth/ transmitted power [40].

There are different ways to calculate the ECC for the MIMO antenna system. First, based on the power at the ports in terms of the scattering parameters at the antenna output ports as in (7) which is accurate and applicable for high efficient antennas [41].

$$
\rho_{\mathrm{e}}=\frac{\left|S_{i i}^{*} S_{i j}+S_{j i}^{*} S_{j j}\right|^{2}}{\left(1-\left(\left|S_{i i}\right|^{2}+\left|S_{j i}\right|^{2}\right)\right)\left(1-\left(\left|S_{j j}\right|^{2}+\left|S_{i j}\right|^{2}\right)\right)} .
$$

The formula in (7) becomes inaccurate when the antenna system is not highly efficient. Also, it does not account for the antenna radiation pattern. Therefore, another formula used to calculate the ECC based on the antenna radiation patterns is given in (8) [42]. However, the challenge in far-field approach is that it needs a complex setting for measuring the radiated far-field.

$$
\rho_{\mathrm{e}}=\frac{\left|\iint_{4 \pi} \mathbf{F}_{i}(\theta, \Phi) \cdot \mathbf{F}_{j}(\theta, \Phi) \mathrm{d} \Omega\right|^{2}}{\iint_{4 \pi}\left|\mathbf{F}_{i}(\theta, \Phi)\right|^{2} \mathrm{~d} \Omega \iint_{4 \pi}\left|\mathbf{F}_{j}(\theta, \Phi)\right|^{2} \mathrm{~d} \Omega} .
$$




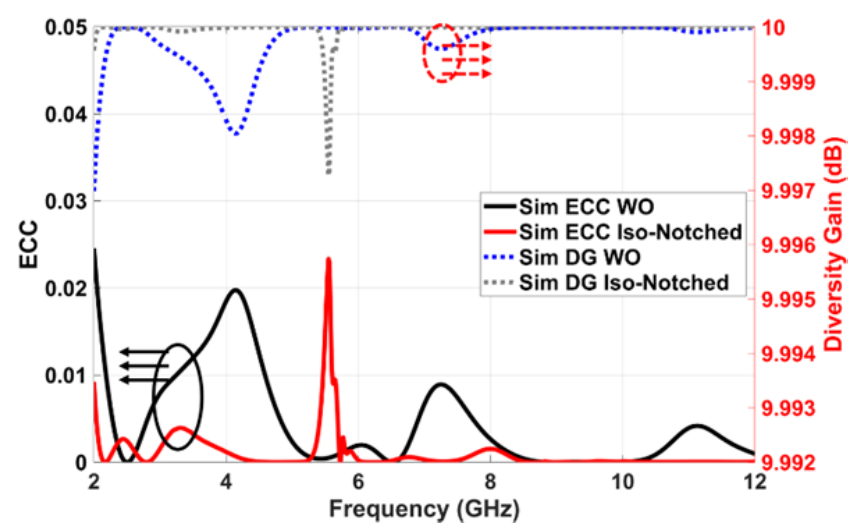

Fig. 15. The simulated envelope correlation and diversity gain from S-parameters formula.

The zero-correlation value is the ideal case but the accepted limit of ECC for uncorrelated MIMO antenna is to be $<0.5$. As it is shown in Fig. 15, the ECC in case of correlated UWB antenna compared to the notched-UWB. MIMO antenna is calculated from the S-parameters formula which is below 0.01 for the entire band except at the notching band centered at $5.8 \mathrm{GHz}$. Secondly, the diversity gain was calculated as in (9) and plotted in Fig. 15. The DG is over $9.999 \mathrm{~dB}$ for the entire band except for the same notching band. Any amount of correlation in the MIMO system negatively affects diversity gain, where the DG is appeared to be decreased at the resonance frequency at which the notch has occurred in all the results.

$$
D G=10 \sqrt{1-\left(\rho_{\mathrm{e}}\right)^{2}}
$$

Based on the measured S parameters, the ECC and diversity gain are plotted in Fig. 16. It can be observed that the ECC values for the entire band in case of the proposed notched-UWB MIMO antenna are below 0.01 and in the other side, for the MIMO antenna DG, it is almost $10 \mathrm{~dB}$ for the entire band. For further comparisons, the ECC for the uncorrelated MIMO system was calculated by means of the radiated far-field pattern (based on (8)) to have a more accurate correlation investigation, as shown in Fig. 17. It can be noticed that the far-field ECC calculation is higher than that from S-parameters calculation but still less than 0.01 , which is within the standard.

The multiplexing efficiency of the antenna (10) is

$$
\eta_{\mathrm{mux}} \approx \sqrt{\eta_{1} \eta_{2}\left(1-\rho_{\mathrm{c}}\right)}
$$

where $\rho_{\mathrm{c}}$ is the envelope correlation coefficient between the radiating elements, $\eta_{1}$ and $\eta_{2}$ are the total efficiencies of the two antenna radiators in the MIMO system. $\eta_{\text {mux }}$ is plotted in Fig. 18 varying with frequencies compared to the correlated antenna (without notching and array of isolation). It is noticed that the multiplexing efficiencies are enhanced after the notching resonance since they are above $91 \%$ for the entire band that is after the notching effect.

Finally, the channel capacity loss $C C L$ between antenna elements is calculated as in (11)-(13) [43].

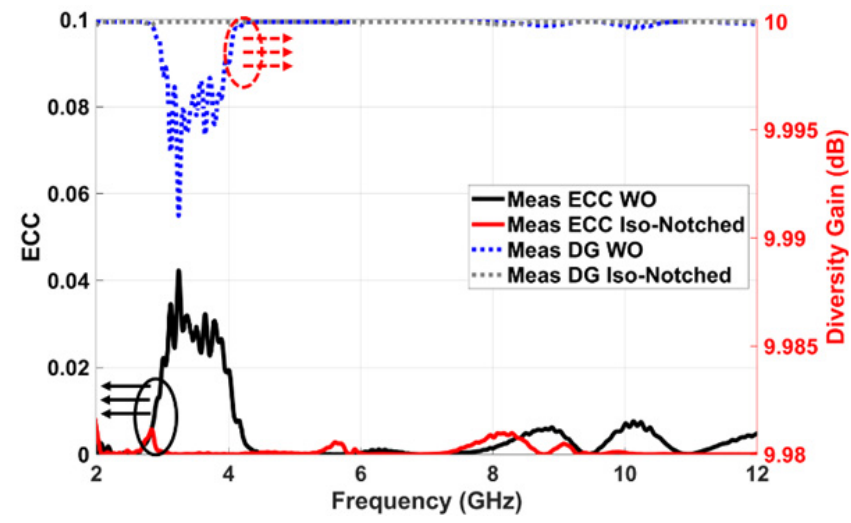

Fig. 16. The measured envelope correlation and diversity gain from S-parameters formula.

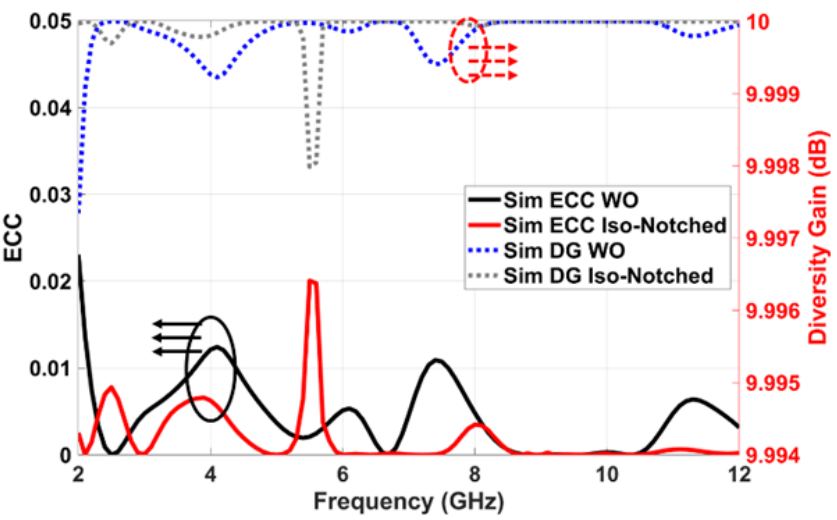

Fig. 17. Envelope correlation and diversity gain from far-field formula.

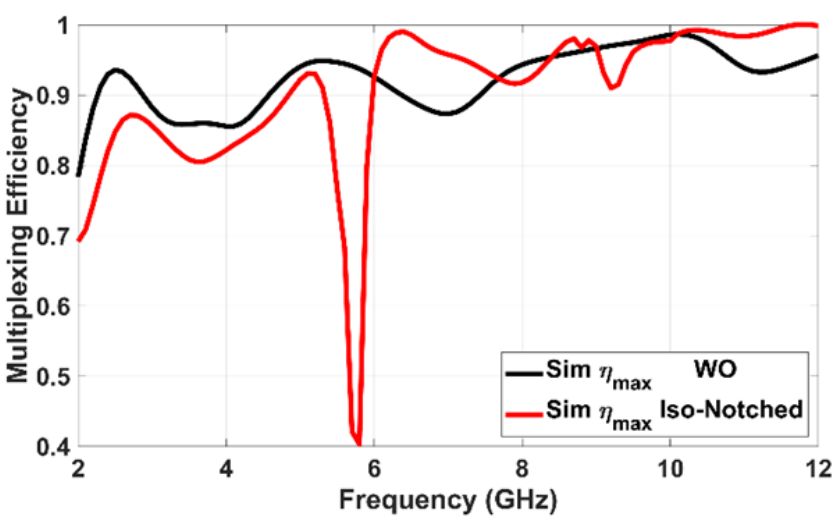

Fig. 18. The multiplexing efficiency for both correlated and isolated-notched MIMO antennas.

$$
\begin{gathered}
C C L=-\log _{2} \operatorname{det}\left(\boldsymbol{\psi}^{\mathrm{R}}\right), \\
\boldsymbol{\psi}^{\mathrm{R}}=\left[\begin{array}{ll}
\rho_{11} & \rho_{12} \\
\rho_{21} & \rho_{22}
\end{array}\right]
\end{gathered}
$$

where

$$
\begin{gathered}
\rho_{i i}=1-\left(\left|S_{i i}\right|^{2}+\left|S_{i j}\right|^{2}\right) \\
\rho_{i j}=-\left(S_{i i}^{*} S_{i j}+S_{j i}^{*} S_{i j}\right) \text { for } i, j=1 \text { or } 2 .
\end{gathered}
$$


The simulated CCL is plotted in Fig. 19 where its average equals $0.2 \mathrm{bits} / \mathrm{s} / \mathrm{Hz}$. Therefore, it can be claimed that the achieved channel capacity loss values are lower than the reference value of $0.4 \mathrm{bits} / \mathrm{s} / \mathrm{Hz}$ within the UWB bandwidth except at the band within notching effect [43].

For further confirmation of the proposed UWB notch MIMO antenna with recent similar work, a performance comparison is summarized in Tab. 1. It can be observed that the proposed isolated-notched UWB MIMO antenna has good isolation for the entire band. Also, the good isolation occurred with very good envelope correlation value (0.01) between the MIMO elements among the ECC values of the compared work in such UWB MIMO systems.

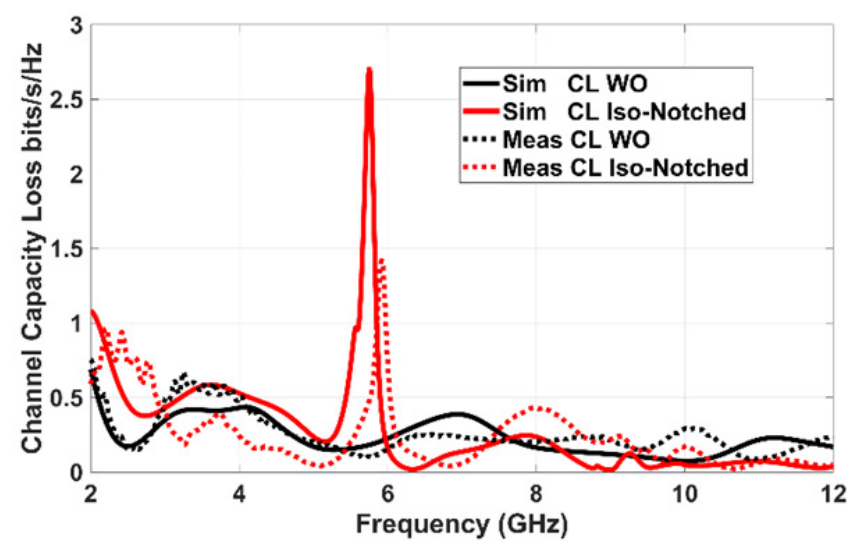

Fig. 19. The simulated and measured channel capacity loss for both cases of MIMO antennas.

\begin{tabular}{|c|c|c|c|}
\hline Ref. & BW (\%) & Technique & Isolation $(\mathrm{dB})$ \\
\hline [18] & $\begin{array}{l}\text { UWB } \\
(109 \%)\end{array}$ & $\begin{array}{l}\text { Etching slot in } \\
\text { the ground }\end{array}$ & $\begin{array}{c}10-30 \mathrm{~dB}(2.2-5.2 \mathrm{GHz}), \\
7 \mathrm{~dB}(8.2-0.2 \mathrm{GHz})\end{array}$ \\
\hline [19] & $\begin{array}{l}\text { UWB } \\
(148 \%)\end{array}$ & $\begin{array}{l}\text { T-crossed shaped } \\
\text { stub }\end{array}$ & $\begin{array}{c}10 \mathrm{~dB}(3-4 \mathrm{GHz}), \\
10-20 \mathrm{~dB}(6.2-8.8 \mathrm{GHz})\end{array}$ \\
\hline [20] & $\begin{array}{l}\text { UWB } \\
(106 \%)\end{array}$ & $\begin{array}{l}\text { Opposite } \\
\text { orientation }\end{array}$ & $\begin{array}{c}-15 \mathrm{~dB} \text { isolation for all } \\
\text { the band except around } \\
5 \mathrm{GHz}\end{array}$ \\
\hline [21] & $\begin{array}{l}\text { UWB } \\
(100 \%)\end{array}$ & $\begin{array}{l}\text { I-shaped slot and } \\
\text { patch, } \\
\text { U-shaped slot and } \\
\text { GND stub }\end{array}$ & $\begin{array}{l}5-10 \mathrm{~dB} \text { (using stub), } \\
5-20 \mathrm{~dB} \text { (using patch) } \\
\text { except at } 6.5-8.5 \mathrm{GHz}\end{array}$ \\
\hline [22] & $\begin{array}{l}\text { UWB } \\
(116 \%)\end{array}$ & Slot in the GND & $8 \mathrm{~dB}(3-4.5 \mathrm{GHz})$ \\
\hline [24] & $\begin{array}{l}\text { UWB } \\
(109 \%)\end{array}$ & $\begin{array}{c}\text { FSS /Polystyrene } \\
\text { block }\end{array}$ & $5-25 \mathrm{~dB}$ \\
\hline [25] & $\begin{array}{l}\text { UWB } \\
(112 \%)\end{array}$ & $\begin{array}{l}\text { T-shaped stub, } \\
\text { GND slot }\end{array}$ & $\begin{array}{c}4-13 \mathrm{~dB}(4.2-11 \mathrm{GHz}), \\
5 \mathrm{~dB}(2.4-5 \mathrm{GHz})\end{array}$ \\
\hline [26] & $\begin{array}{l}\text { UWB } \\
(106 \%)\end{array}$ & $\begin{array}{l}\text { Decoupling metal } \\
\text { strips with vias }\end{array}$ & $\begin{array}{c}10-20 \mathrm{~dB} \text { (after } 9.2 \mathrm{GHz} \\
\text { become worse) }\end{array}$ \\
\hline [31] & UWB & $\begin{array}{l}\text { Meta strips in } \\
\text { GND }\end{array}$ & $15 \mathrm{~dB}(3.1-10.6 \mathrm{GHz})$ \\
\hline [32] & UWB & $\begin{array}{c}\text { Meta T- strips in } \\
\text { GND }\end{array}$ & $12 \mathrm{~dB}(3 \mathrm{GHz}-11 \mathrm{GHz})$ \\
\hline $\begin{array}{l}\text { This } \\
\text { Work }\end{array}$ & $\begin{array}{c}\text { UWB } \\
(120 \%)\end{array}$ & EBG array & $10-20 \mathrm{~dB}(2-12 \mathrm{GHz})$ \\
\hline
\end{tabular}

Tab. 1. A comparison between the proposed UWB MIMO antenna and similar recent published work.

\section{Conclusion}

A good candidate two-element MIMO antenna (3.1 GHz-10.6 GHz, UWB bandwidth with a notch at $5.8 \mathrm{GHz}$ ) is introduced. The notch frequency is achieved using one EBG particle filtering the input current for the UWB antenna. Moreover, high isolation (more than $20 \mathrm{~dB}$ ) is achieved between the MIMO elements using an array of wideband mushroom-like EBG between the radiating element. In addition to the used simple structure, the antenna size is only $90 \times 30 \mathrm{~mm}^{2}$. Good MIMO parameters have been confirmed using both simulated and measured results. The MIMO antenna demonstrated typical MIMO parameters in terms of ECC less than 0.04 and DG greater than $9.999 \mathrm{~dB}$, multiplexing efficiency greater than $91 \%$ and channel capacity loss less than $0.2 \mathrm{bits} / \mathrm{s} / \mathrm{Hz}$.

\section{References}

[1] TELATAR, I., TSE, D. N. C. Capacity and mutual information of wideband multipath fading channels. IEEE Transactions on Information Theory, 2000, vol. 46, no. 4, p. 1384-1400. DOI: $10.1109 / 18.850678$

[2] PAUlRAJ, A. J., GORE, D., NABAR, R. U., et al. An overview of MIMO communications-A key to gigabit wireless. Proceedings of the IEEE, 2004, vol. 92, no. 2, p. 198-218. DOI: 10.1109/JPROC.2003.821915

[3] LI, Q., ABDULLAH, M., CHEN, X. Defected ground structure loaded with meandered lines for decoupling of dual-band antenna. Journal of Electromagnetic Waves and Applications, 2019, vol. 33, no. 13, p. 1764-1775. DOI: 10.1080/09205071.2019.1643261

[4] WU, C. H., ZHOU, G. T., WU, Y. L., et al. Stub-loaded reactive decoupling network for two-element array using even-odd analysis. IEEE Antennas and Wireless Propagation Letters, 2013, vol. 12, p. 452-455. DOI: 10.1109/LAWP.2013.2255255

[5] SELVARAJU, R., JAMALUDDIN, M. H., KAMARUDIN, M. R., et al. Mutual coupling reduction and pattern error correction in a 5G beamforming linear array using CSRR. IEEE Access, 2018 , vol. 6, p. 65922-65934. DOI: 10.1109/ACCESS.2018.2873062

[6] IQBAL, A., SARAEREH, O. A., AHMAD, A. W., et al. Mutual coupling reduction using F-shaped stubs in UWB-MIMO antenna. IEEE Access, 2018, vol. 6, p. 2755-2759. DOI: 10.1109/ACCESS.2017.2785232

[7] MOHAMED, I., ABDAlla, M., MITKEES, A. A. Perfect isolation performance among two-element MIMO antennas. AEU International Journal of Electronics and Communications, 2019, vol. 107, p. 21-31. DOI: 10.1016/j.aeue.2019.05.014

[8] IBRAHIM, A., ABDALlA, M. A., HU, Z. Design of a compact MIMO antenna with asymmetric coplanar strip-fed for UWB applications. Microwave and Optical Technology Letters, 2017, vol. 59, no. 1, p. 31-36. DOI: 10.1002/mop.30208

[9] ASSIMONIS, S. D., YIOULTSIS, T. V., ANTONOPOUlOS, C. $\mathrm{S}$. Design and optimization of uniplanar EBG structures for low profile antenna applications and mutual coupling reduction. IEEE Transactions on Antennas and Propagation, 2012, vol. 60, no. 10, p. 4944-4949. DOI: 10.1109/TAP.2012.2210178

[10] SWATI, Y. Design and Analysis of Band Notched Antennas for $U W B$ and MIMO Wireless Applications. Uttarakhand Technical University, 2018. 
[11] FEDERAL COMMUNICATIONS COMMISSION. Revision of Part 15 of the Commission's Rules Regarding Ultra-Wideband Transmission Systems. First Rep. Order, FCC 02-48, 2002.

[12] GHOSH, A., MANDAL, T., DAS, S. Design and analysis of triple notch ultrawideband antenna using single slotted electromagnetic bandgap inspired structure. Journal of Electromagnetic Waves and Applications, 2019, vol. 33, no. 11, p. 1391-1405. DOI: $10.1080 / 09205071.2019 .1609377$

[13] ABDALlA, M. A., AL-MOHAMADI, A. A., MOHAMED, I. S. A miniaturized dual band EBG unit cell for UWB antennas with high selective notching. International Journal of Microwave and Wireless Technologies, 2019, vol. 11, no. 10, p. 1035-1043. DOI: $10.1017 / \mathrm{S} 1759078719000710$

[14] LI, T., ZHAI, H. Q., LI, G. H., et al. Design of compact UWB band-notched antenna by means of electromagnetic- bandgap structures. Electronics Letters, 2012, vol. 48, no. 11, p. 608-609. DOI: $10.1049 / \mathrm{el} .2012 .0972$

[15] KAISER, T., ZHENG, F., DIMITROV, E. An overview of ultrawideband systems with MIMO. Proceedings of IEEE, 2009, vol. 97, no. 2, p. 285-312. DOI: 10.1109/JPROC.2008.2008784

[16] ABDELRAHEEM, A. M., ABDALLA, M. A. Bi-directional UWB MIMO antenna for superior spatial diversity, and/or multiplexing MIMO performance. Wireless Personal Communications, 2018, vol. 101, no. 3, p. 1379-1394. DOI: $10.1007 / \mathrm{s} 11277-018-5767-5$

[17] DENG, J. Y., GUO, L. X., LIU, X. L. An ultrawideband MIMO antenna with a high isolation. IEEE Antennas and Wireless Propagation Letters, 2016, vol. 15, p. 182-185. DOI: 10.1109/LAWP.2015.2437713

[18] KUMAR, R., SURUSHE, G. Design of microstrip-fed printed UWB diversity antenna with tee crossed shaped structure. Engineering Science and Technology, an International Journal, 2016, vol. 19, no. 2, p. 946-955. DOI: 10.1016/j.jestch.2015.10.006

[19] NASER, S., DIB, N. Design and analysis of super-formula-based UWB monopole antenna and its MIMO configuration. Wireless Personal Communications, 2017, vol. 94, no. 4, p. 3389-3401. DOI: $10.1007 / \mathrm{s} 11277-016-3782-\mathrm{y}$

[20] ZHANG, J. Y., ZHANG, F., TIAN, W. P., et al. ACS-fed UWBMIMO antenna with shared radiator. Electronics Letters, 2015, vol. 51 , no. 17 , p. 1301-1302. DOI: 10.1049/el.2015.1327

[21] REN, J., HU, W., YIN, Y., et al. Compact printed MIMO antenna for UWB applications. IEEE Antennas and Wireless Propagation Letters, 2014, vol. 13, p. 1517-1520. DOI: 10.1109/LAWP.2014.2343454

[22] YETISIR, E., CHEN, C. C., VOLAKIS, J. L. Low-profile UWB 2port antenna with high isolation. IEEE Antennas and Wireless Propagation Letters, 2014, vol. 13, p. 55-58. DOI: 10.1109/LAWP.2013.2296045

[23] BILAL, M., SALEEM R., ABBASI, H. H., et al. An FSS-based nonplanar quad-element UWB-MIMO antenna system. IEEE Antennas and Wireless Propagation Letters, 2017, vol. 16, p. 987-990. DOI: 10.1109/LAWP.2016.2615884

[24] LIU, L., CHEUNG, S. W., YUK, T. I. Compact MIMO antenna for portable UWB applications with band-botched characteristic. IEEE Transactions on Antennas and Propagation, 2015, vol. 63, no. 5, p. 1917-1924. DOI: 10.1109/TAP.2015.2406892

[25] TANG, T. C., LIN, K. H. An ultrawideband MIMO antenna with dual band-notched function. IEEE Antennas and Wireless Propagation Letters, 2014, vol. 13, p. 1076-1079. DOI: 10.1109/LAWP.2014.2329496

[26] TANG, Z., ZHAN, J., WU, X., et al. Design of a compact UWBMIMO antenna with high isolation and dual band-notched characteristics. Journal of Electromagnetic Waves and Applications,
2020, vol. $34, \quad$ no. $4, \quad$ p. $500-513$. DOI: $10.1080 / 09205071.2020 .1724200$

[27] LIU, Y. Y., TU, Z. H. Compact differential band-notched steppedslot UWB-MIMO antenna with common-mode suppression. IEEE Antennas and Wireless Propagation Letters, 2016, vol. 16, p. 593-596. DOI: 10.1109/LAWP.2016.2592179

[28] TOKTAS, A. G-shaped band-notched ultra-wideband MIMO antenna system for mobile terminals. IET Microwaves, Antennas \& Propagation, 2016, vol. 11, no. 5, p. 718-725. DOI: 10.1049/iet-map.2016.0820

[29] LI, J. F., CHU, Q. X., LI, Z. H., et al. Compact dual band-notched UWB MIMO antenna with high isolation. IEEE Transactions on Antennas and Propagation, 2013, vol. 61, no. 9, p. 4759-4766. DOI: 10.1109/TAP.2013.2267653

[30] KANG, L., LI, H., WANG, X., et al. Compact offset microstripfed MIMO antenna for band-notched UWB applications. IEEE Antennas and Wireless Propagation Letters, 2015, vol. 14, p. 1754-1757. DOI: 10.1109/LAWP.2015.2422571

[31] LI, Z., YIN, C., ZHU, X. Compact UWB MIMO Vivaldi antenna with dual band-notched characteristics. IEEE Access, 2019, vol. 7 , p. 38696-38701. DOI: 10.1109/ACCESS.2019.2906338

[32] KUMAR, A. G., YADAV, S., RAMBABU, K. Design of ultracompact UWB antenna with band-notched characteristics for MIMO applications. IET Microwaves, Antennas \& Propagation, 2018 , vol. 12 , no. 12 , p. $1895-1900$. DOI: $10.1049 /$ ietmap.2018.0012

[33] AZARM, B., NOURINIA, J., GHOBADI, C., et al. A compact WiMAX band-notched UWB MIMO antenna with high isolation. Radioengineering, 2018, vol. 27, no. 4, p. 983-989. DOI: $10.13164 / \mathrm{re} .2018 .0983$

[34] QUDDUS, A., SALEEM, R., SHAFIQUE, M. F. Compact electronically reconfigurable WiMAX band-notched ultrawideband MIMO antenna. Radioengineering, 2018, vol. 27, no. 4, p. 998-1003. DOI: 10.13164/re.2018.0998

[35] SAXENA, G., JAIN, P., AWASTHI, Y. K. High diversity gain super-wideband single band-notch MIMO antenna for multiple wireless applications. IET Microwaves, Antennas \& Propagation, 2020, vol. 14, no. 1, p. 109-119. DOI: 10.1049/iet-map.2019.0450

[36] THAKUR, E., JAGLAN, N., GUPTA, S. D. Design of compact triple band-notched UWB MIMO antenna with TVC-EBG structure. Journal of Electromagnetic Waves and Applications, 2020, vol. 34, p. 1-15. DOI: 10.1080/09205071.2020.1775136

[37] NAZIF, D., RABIE, R., ABDALLA, M. A., Mutual coupling reduction in two elements UWB notch antenna system. In 2017 IEEE AP-S International Antenna and Propagation Symposium Digest. San Diego (CA, USA), 2017, p. 1887-1888. DOI: 10.1109/APUSNCURSINRSM.2017.8072986

[38] TIAN, R., LAU, B. K., YING, Z. Multiplexing efficiency of MIMO antennas. IEEE Antennas and Wireless Propagation Letters, 2011, vol. 10, p. 183-186. DOI: 10.1109/LAWP.2011.2125773

[39] CHUAH, C. N., TSE, D. N., KAHN, J. M., et al. Capacity scaling in MIMO wireless systems under correlated fading. IEEE Transactions on Information Theory, 2002, vol. 48, no. 3, p. $637-650$. DOI: $10.1109 / 18.985982$

[40] BLANCH, S., ROMEU, J., CORBELLA, I. Exact representation of antenna system diversity performance from input parameter description. Electronics Letters, 2003, vol. 39, no. 9, p. 705-707. DOI: $10.1049 / \mathrm{el}: 20030495$

[41] SHIN, H., LEE, J. H. Capacity of multiple-antenna fading channels: Spatial fading correlation, double scattering, and keyhole. IEEE Transactions on Information Theory, 2003, vol. 49, no. 10, p. 2636-2647. DOI: 10.1109/TIT.2003.817439 
[42] VAughan, R. G., ANDERSEN, J. B. Antenna diversity in mobile communications. IEEE Transactions on Vehicular Technology, 1987, vol. 36, no. 4, p. 149-172. DOI: 10.1109/TVT.1987.24115

[43] CHOUKIKER, Y. K., SHARMA, S. K., BEHERA, S. K. Hybrid fractal shape planar monopole antenna covering multiband wireless communications with MIMO implementation for handheld mobile devices. IEEE Transactions on Antennas \& Propagation, 2014, vol. 62, no. 3, p. 1483-1488. DOI: 10.1109/TAP.2013.2295213

\section{About the Authors ...}

Donya Z. NAZIF was born in 1994. She received the B.Sc. degree in Electrical Engineering from the Electrical and Communication Engineering Department, Modern Science and Arts University, Giza, Egypt in 2017. Currently, she is pursuing her M.Sc. degree in Electrical Engineering at the Arab Academy for Science, Technology \& Maritime Transport, Giza, Egypt. Her research interests include mutual coupling reduction, MIMO antennas, UWB antennas. Also, she has a good experience in electromagnetic bandgap structures (EBGs) design.

Ibrahim MOHAMED was born in 1992. He received the B.Sc. and M.Sc. degrees in Electrical Engineering from the Electrical Engineering Department, Military Technical College, Cairo, Egypt, in 2014 and 2020. Currently, he is pursuing his Ph.D. degree in Electrical Engineering at the Military Technical College, Cairo, Egypt. His research interests include mutual coupling reduction in thin, low profile antennas, MIMO antennas, antenna arrays. Also, he has a good experience in defected ground structures (DGS), artificial magnetic conductors (AMC) and electromagnetic bandgap structures (EBGs) design. He is currently a reviewer in many high ranked electromagnetic journals.
Abdelhamid Ali GAAFAR was born in 1955. He received the B.Sc. degree in Electrical Engineering from the Electrical Engineering Department, Military Technical College, Cairo, Egypt in 1977. He received the M.Sc. in Electrical Engineering, Al-Azhar University Cairo, Egypt in 1983. He received his Ph.D. in Electrical Engineering in 1989, from Electrical Engineering \& Applied Science, George Washington University, Washington DC. He has been with the Military Technical College since 1989 to 2006, then from 2006 - now as a prof. of Electrical Engineering at the Electronic and Communication Dept., Arab Academy for Science and Technology and Maritime Transport, Cairo Branch

Mahmoud ABDALLA was born in 1973. He received the B.Sc. and M.Sc. degrees in Electrical Engineering from the Electrical Engineering Department, Military Technical College, Cairo, Egypt in 1995 and 2000. He received the Ph.D. degree from the School of Electrical Engineering, University of Manchester, UK, in 2009. He is now a professor and leading the electromagnetic waves group in the Electronic Engineering Department, Military Technical College. Dr. Mahmoud was the recipient of Egyptian encouragement state prize for engineering sciences in 2014 and prize of innovation in 2019 . He published more than 200 peer-reviewed journal and conference papers. His research has focused on miniaturized, multiband and wideband microwave/millimeter antennas, components and absorbing materials with great attention to employ metamaterial/EBG, structures. Dr. Mahmoud Abdalla is a senior member of the IEEE and the European Microwave Association EuMA. He is currently a reviewer in many high ranked electromagnetic journals. Also, he was awarded the top $1 \%$ Publon worldwide reviewer award for 2018 and 2019. 